\title{
O que diz uma manchete? \\ Uma leitura \\ construcional \\ de manchetes \\ argentinas e brasileiras
}

Paulo Pinheiro Correa

Recebido em: 30 de agosto de 2019

Aceito em: 19 de outubro de 2019
Professor de Língua Espanhola da Universidade Federal Fluminense (UFF), Doutor e Mestre em Linguística (UFRJ), com pósdoutorado na Universidad Complutense de Madrid, Espanha (2014-2015).

Contato: papicorrea@gmail.coml Brasil 


\section{PALAVRAS-CHAVE: sramática de construções; manchetes; espanhol argentino; português brasileiro; frame semântico.}

KEYWORDS: construction grammar; headlines; Argentinean Spanish; Brazilian Portuguese; semantic frame.
Resumo: Neste trabalho, dentro do instrumental teórico da Gramática de Construçães baseada no Uso (Goldbers 1995, 2006, entre outros) foram identificadas as construções de estrutura argumental instanciadas em manchetes em 300 dados da seção policial de dois jornais argentinos e dois brasileiros, com a finalidade de compará-las e definir suas propriedades. $\bigcirc$ resultado da análise dos 150 dados de cada língua revelou que: (a) no gênero discursivo manchete nos jornais de Buenos Aires é usada uma variedade maior de construções (12 tipos) que nas manchetes dos jornais do Rio de Janeiro (5 tipos) e (b) a escolha exata de uma entre as 12 manchetes argentinas usadas está ligada à relevância/irrelevância pragmática do fato informado e impede leituras inadequadas. Nos dados brasileiros, as construções usadas não mostraram a mesma especificação semântica e pragmática, expressando participantes semanticamente previstos e pragmaticamente irrelevantes.

Abstract: In this paper, within Usage-Based Construction Grammar framework (Goldbers 1995, 2006 among others) language constructions instantiated in newspaper headlines in Spanish and Portuguese were compared. 300 data from crime section from Argentinean and Brazilian newspapers were analyzed and the result of the analysis of 150 headlines from each language shows that: (a) in the Argentinean headlines corpus more constructions were instantiated (12 types) than in the Brazilian headlines corpus ( 5 types) and (b) the exact choice of a construction from Spanish array depends on the semantic predictability and the pragmatic relevance of participants of the event. The chosen construction helps preventing misguided readings. Brazilian Portuguese constructions in the corpus, in turn, were less diverse, and were less specified for meaning, expressing semantically predictable and prasmatically irrelevant participants. 
O QUE DIZ UMA MANCHETE? UMA LEITURA CONSTRUCIONAL DE MANCHETES ARGENTINAS E BRASILEIRAS

Paulo Pinheiro Correa

\section{INTRODUÇÃO.}

De acordo com o modelo teórico denominado Gramática de Construçóes baseada no Uso (GCBU) (Goldberg 1995, 2006), uma construção, desde as mais concretas até as mais abstratas, consiste de um pareamento de forma e função que perfaz todo o sistema gramatical em determinada língua (configurando-se de maneira própria em cada uma de suas variedades). Dentro deste panorama, pretendemos explorar os significados expressos nas escolhas das construçôes que são instanciadas por manchetes argentinas de dois jornais de Buenos Aires, compiladas em um corpus e comparar, em um corpus brasileiro, com as construçôes que são instanciadas por manchetes de jornais brasileiros. O objetivo é oferecer uma comparação cognitivamente embasada, mostrando comparativamente a gama de construçóes que se manifestam no corpus em uma e outra variedade (types), bem como aquelas construçóes que foram mais usadas (tokens).

Assim, de acordo com o postulado da GCBU, em um elenco de manchetes argentinas como os três exemplos abaixo extraídos do corpus:

(i) Una mujer entregó a su hijo tras un homicidio y advirtió: "Se cree impune"

(ii) Echaron del país a la madre de un clan narco de la villa 31

(iii) Persecución fatal en San Miguel del Monte: mejora Rocío y evalúan operarla

existe um significado constante em cada uma das construçóes abstratas instanciadas pelo enunciador quando expressa o conteúdo, neste caso 
específico, das manchetes. Pretendemos mostrar que em espanhol este significado inerente conduz a leituras adequadas do evento referido na manchete e a escolha adequada da construçáo que será instanciada impede inclusive leituras inadequadas dos eventos referidos. Depois analisaremos como se deu essa dinâmica nos dados brasileiros.

O trabalho é estruturado como segue: na seção 2 é apresentado brevemente o gênero discursivo manchete de jornal, do ponto de vista de estudiosos do mundo hispânico, com uma discussão das características desse gênero. A seção 3 está destinada a apresentar e discutir a fundamentação teórica deste trabalho. A seção 4 é dedicada à metodologia empregada na obtenção de dados. A seção 5 está destinada à apresentação e discussão dos resultados e a 6 , à conclusão.

\section{O GÊNERO DISCURSIVO MANCHETE DE JORNAL}

Alarcos Llorach (1977) define este gênero jornalístico como um rótulo, de características muito peculiares, que identifica prontamente para o leitor o conteúdo do material linguístico imediatamente contíguo a ele. O autor é um dos primeiros a observar que as manchetes se diferenciam "com nitidez das manifestaçóes linguísticas habituais, ainda que os materiais linguísticos empregados pertençam em um e em outro caso aos mesmos repertórios que cada língua oferece a seu usuário." (ALARCOS LLORACH, 1977, 129).

Nadal Palazón (2012), ao analisar 3689 manchetes de dez jornais de dez países diferentes, atribui a estas quatro características constantes e quatro, 
O QUE DIZ UMA MANCHETE? UMA LEITURA CONSTRUCIONAL DE MANCHETES ARGENTINAS E BRASILEIRAS

variáveis. As constantes são as que apareceram em todos os jornais: (a) estrutura expressiva bipartida, nas manchetes que envolvem, por exemplo, um tópico e um comentário; (b) elipse de algum componente como determinantes ou substantivos; (c) estruturas nominais, típicas das manchetes sem verbo e (d) presente histórico, para dar atualidade à notícia.

As características variáveis, por sua vez, são as que apareceram em determinado grupo de jornais e náo em outro, ou quando apareceram, foram pouco frequentes. Entre elas se destacam o uso da terceira pessoa impessoal e o verbo no início da manchete, que o autor atribui majoritariamente às manchetes hispanoamericanas.

Em estudos brasileiros sobre a manchete, Barros Filho (2008) comenta que a manchete "constrói a representação que o leitor faz do texto como um todo antes de lê-lo.” Abraçado e Silva (2014), por sua vez levantaram características ligadas à transitividade em manchetes de jornais online do Rio de Janeiro e no seu corpus predominaram as manchetes com dois participantes, com sujeitos que, em sua maioria eram abstratos e acompanhados de objeto direto, em 142 de 166 manchetes analisadas. Houve grande quantidade de verbos de ação; predominou o aspecto imperfectivo e o caráter não pontual dos eventos. Os sujeitos, tipicamente agentivos, eram agentes não prototípicos, por serem abstratos ('PM detém'/'sindicato critica'/'conselho aprova'). Da mesma maneira, mesmo não sendo agentes prototípicos, eram agentes abstratos volitivos, em sua maioria (Abraçado; Silva, 2014, 243). 


\section{FundAMENTAÇÃO TEÓRICA.}

A Gramática de Construçóes baseada no Uso (doravante, GCBU) é um modelo de análise gramatical que reconhece a noção de construçâo como elemento básico de constituição da linguagem, e de acordo com este modelo:

a) o sistema linguístico é um conjunto de construções, que vão desde as mais simples e concretas (por exemplo, lexicais e morfológicas) até as mais complexas e esquemáticas (por exemplo, as sintáticas);

b) a aprendizagem de uma língua consiste na aprendizagem desse conjunto de construçóes e o conhecimento linguístico de um falante corresponde ao conhecimento de um inventário estruturado dessas construçóes;

c) a experiência linguística concreta do falante interfere de maneira contínua na organização do seu conhecimento linguístico;

d) as construções são adquiridas de maneira redundante e abrangente, e todos os elementos contextuais e situacionais, além dos linguísticos, são reconhecidos pela cognição e apreendidos conjuntamente;

e) a linguagem emerge no indivíduo como um desenvolvimento integrado aos demais processos cognitivos de domínio geral, não exclusivamente linguísticos (Bybee, 2010; Langacker, 1987, entre outros). Estes processos incluem a rotinização cognitiva, a esquematização, a categorização, a analogia, a abstração, a associação e a armazenagem mnemônica rica (Bybee, 2010, 6-8).

Como assinala Goldberg (2006), 
O QUE DIZ UMA MANCHETE? UMA LEITURA CONSTRUCIONAL DE MANCHETES ARGENTINAS E BRASILEIRAS

Paulo Pinheiro Correa

(...) as abordagens construcionistas enfatizam o papel das CONSTRUÇÓES gramaticais: pareamentos convencionalizados de forma e função. Além disso, as abordagens construcionistas geralmente enfatizam que as línguas são aprendidas - que elas são CONSTRUIIDAS com base no insumo que chega junto com definiçóes de ordem cognitiva geral, pragmáticas e de processamento ${ }^{1}$. (Goldberg, 2006, 3)

De acordo com este quadro teórico, uma construção é definida como um pareamento convencional de forma (características sintáticas, morfológicas e fonológicas) e significado, chamado por Goldberg de função, que compreende não apenas suas características semânticas, mas também pragmáticas (contextuais, situacionais e discursivas). A construção, enquanto pareamento de forma e função é específica de cada língua, ou seja, o valor de cada construção é considerado válido dentro de um sistema linguístico e não é válido para outro. Este pareamento é inseparável e se dá através de elos de correspondência simbólica.

Entre os princípios psicológicos relevantes para a organização da linguagem propostos por Goldberg $(1995,67)$ estão: (a) o princípio da motivação maximizada, e (b) o princípio da não sinonímia. De acordo com o primeiro, se uma construção guarda relação sintática com outra, o sistema da primeira é motivado, por haver algum grau de relação semântica entre elas. Este princípio, como operador teórico, oferece meios para se chegar a uma descrição consistente da motivação para as formas linguísticas emergentes e das relações que as formas guardam entre si em forma de rede, que estão vinculadas à noção de herança.

1 Tradução nossa do original em inglês: “(...) constructionist approaches emphasize the role of grammatical constructions: conventionalized pairings of form and function. In addition, constructionist approaches generally emphasize that languages are learned - that they are constructed on the basis of the input together with general cognitive, pragmatic, and processing constraints." 
Já o segundo postula que se duas construções são sintaticamente diferentes, elas devem guardar diferenças, pelo menos em um dos níveis relacionados à função, o semântico ou o pragmático, onde entra a estrutura informativa.

Estes princípios refletem a organização da língua, neste modelo, como um inventário de construçôes, das mais prototípicas às mais periféricas de cada tipologia, todas elas inter-relacionadas em rede, e guardando relaçóes de herança entre si, no que se refere às suas propriedades formais e funcionais: semânticas e pragmáticas. Estas relaçôes se dão por meio de laços polissêmicos e extensōes metafóricas.

Uma das premissas da Gramática de Construçôes é a do significado intrínseco que a construção tem dentro de determinado sistema. Assim, todas as construçôes de uma língua têm uma função que emerge no sistema e que não pode ser extraída ou prevista a partir da soma das suas partes, de maneira que as construçôes instanciam sentidos independentemente dos itens léxicos que as compóem. Goldberg (1995) demonstra o alcance deste postulado analisando algumas construçôes sintáticas. Uma das construçôes estudadas por ela é a bitransitiva. Esta construção abstrata, de forma [SUJEITO VERBO OBJ1 OBJ2], como no exemplo concreto Sally baked her sister a cake (Sally preparou um bolo para a irmã dela), instancia um significado específico aos eventos transmitidos através da sua forma. Esta construção tem uma inserção no sistema gramatical e propriedades diferentes das de sua paráfrase com a preposição to, Sally baked a cake to her sister. Através da descrição e análise do funcionamento das construçôes, a autora propôe resolver questôes longamente problemáticas como, por 
O QUE DIZ UMA MANCHETE? UMA LEITURA CONSTRUCIONAL DE MANCHETES ARGENTINAS E BRASILEIRAS

exemplo, a da estrutura argumental do verbo, procurando demonstrar que, na perspectiva de um continuum entre léxico e sintaxe, o significado de um verbo só se completa em conjunto com o significado inerente da construção que ele vier a instanciar, podendo instanciar diferentes construçôes, o que propicia a emergência de significados diferentes.

As construçóes que instanciam as manchetes neste trabalho são basicamente todas elas comuns a todo o sistema linguístico. Algumas delas parecem ser próprias do gênero em questão, o que será indicado na seção correspondente.

\section{Metodologia.}

A metodologia consistiu da obtenção de 150 dados de manchetes da mesma variedade de língua e exatamente da mesma editoria dos dois maiores jornais argentinos, Clarín e La Nación, ambos publicados diariamente na cidade de Buenos Aires, capital do país, e da obtenção de outros 150 dados do português brasileiro, extraídos dos jornais O Dia e Extra, do Rio de Janeiro, no mesmo período. Consideramos, com Sasse (2006) e Lambrecht (1994, 2000), que a topicalidade pode influenciar a forma das construçóes e a leitura que é feita das manchetes. Para controlar melhor essa possibilidade, observamos que apenas na editoria de manchetes criminais seria possível isolar ou controlar essa variável, uma vez que tal editoria é o lócus típico da apresentação de eventos inesperados com sujeitos desconhecidos (breaking news). Foram obtidos 75 manchetes de cada jornal, entre os dias 24 de maio e 18 de junho de 2019 para as manchetes argentinas e entre 31 de maio e 26 
de julho do mesmo ano para as brasileiras. Nos dados persistem manchetes do tipo tópico-comentário, em pequeno número, que decidimos não excluir para garantir fidelidade à tipologia de dados.

Algumas manchetes que não se encaixavam nem na tipologia de anunciativas, na classificação de Sasse (2006), nem na de tópico-comentário foram desconsideradas da análise. Dois exemplos delas são: El crimen a traición del peón que no asumía sus fracasos laborales e Asi fue el ataque al custodio de un súper chino: su família dice que buscará al prófugo "por cielo y tierra". Consideramos que estas manchetes sáo majoritariamente nominais e escapam ao propósito deste trabalho. A análise tipológica foi feita inicialmente para os dados argentinos e depois, para os brasileiros.

\section{Resultados. \\ 5.1. Dados argentinos.}

Identificamos doze construçôes instanciadas pelas manchetes argentinas, relacionadas a quatro construçôes esquemáticas das quais são derivadas, a núcleo-complemento, a sujeito-verbo, a verbo-sujeito e a copulativa.

A primeira delas, a transitiva, herda propriedades de duas construçóes abstratas, a núcleo-complemento e a sujeito-verbo; as quatro seguintes são mais diretamente relacionadas à construção núcleo-complemento. São elas: a transitiva de sujeito elíptico, a impessoal com terceira pessoa do plural, impessoal com terceira pessoa do plural com clítico e a impessoal com complemento oracional. 
O QUE DIZ UMA MANCHETE? UMA LEITURA CONSTRUCIONAL DE MANCHETES ARGENTINAS E BRASILEIRAS

Construção 1. transitiva $\left[\mathrm{SUJ}_{\mathrm{AG}} \mathrm{V} \mathrm{OD}(\mathrm{SP})\right]$.

Forma: dois argumentos em torno de um verbo, correspondendo ao sujeito e ao objeto.

Significado: um agente expresso, relevante e não pressuposto age para causar

uma mudança de estado ou de condição numa entidade paciente ${ }^{2}$ (baseado em Goldberg 1995, 2006 e acrescido de informação pragmática). Casos encontrados: 24 do total de 150. Exemplo retirado do corpus:

(1) Un policía golpeó y amenazó de muerte a un chico de 17 años frente a una escuela

Construção 2. Transitiva com sujeito elíptico [V OD (SP) (SV)].

Forma: Verbo na $3^{\text {a }}$ pessoa seguido de objeto direto e sintagmas preposicionais e verbais opcionais.

Significado: um agente pressuposto não expresso age para causar uma mudança de estado ou de condição numa entidade paciente, que é expressa.

Quantidade de casos: 5 de 150. Exemplo:

(2) Robó una pistola para cometer un femicidio

Construção 3. Impessoal com terceira pessoa do plural [V (SP) OBJ (SP)]. Forma: um verbo na terceira pessoa do plural seguido de um objeto com sintagmas preposicionais opcionais.

2 'Paciente' aqui é usado como prototípico de não-agentivo, podendo representar papéis temáticos como paciente, experienciador ou tema. 
Significado: um agente não identificado e não expresso age para causar uma mudança de estado ou de condição numa entidade paciente, que é expressa. Casos encontrados: 87 do total de 150. Exemplo:

(3) Mataron en Moreno a un comisario de San Isidro para robarle el auto

Construção 4. Impessoal de terceira pessoa do plural com clítico ${ }_{\mathrm{CL}} \mathrm{V}$ SP (SP)]. Forma: verbo na terceira pessoa do plural com um clítico de objeto direto anexado seguido de um objeto seguido de um sintagma preposicional e outros SPs opcionais.

Significado: um agente não identificado e não expresso age para causar uma mudança de estado ou de condição numa entidade paciente, pressuposta e não expressa.

Casos encontrados: 7 do total de 150. Exemplo:

(4) Lo detuvieron por simular un secuestro para sacarle 100 mil pesos a su esposa

Construção 5. Impessoal de terceira pessoa do plural com complemento oracional [V CONJ SV].

Forma: um verbo na terceira pessoa do plural seguido de uma conjunçáo integrante ou disjuntiva e um sintagma verbal.

Significado: um agente pressuposto e não expresso age para causar uma mudança de estado ou de condição num estado de coisas identificado.

Casos encontrados: 2 do total de 150. Exemplo: 
O QUE DiZ UMA MANCHETE? UMA LEITURA CONSTRUCIONAL DE MANCHETES ARGENTINAS E BRASILEIRAS

(5) Investigan si dos chicos que murieron arrollados por un tren huian de una patota

As três seguintes construçôes encontradas no corpus guardam relações com a construção copulativa básica. São elas: a passiva, a participial e a estativa.

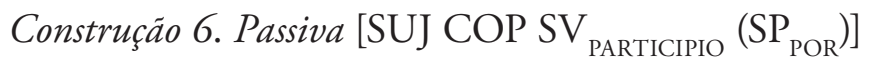

Forma: SN seguido de uma cópula e um particípio seguido de um sintagma preposicional opcional.

Significado: um paciente expresso e não pressuposto sofre uma mudança de estado ou de condição causada por um agente.

Casos encontrados: 3 de 150. Exemplo:

(6) Femicidio en Chacabuco: una médica radióloga fue asesinada por su pareja

Construção 7. Participial [SUJ ${ }_{-\mathrm{AG}} \mathrm{SV}_{\text {PARTICÍPIO }}\left(\mathrm{SP}_{\mathrm{POR})] \text { ]. }}\right.$

Forma: SN seguido de uma conjunção integrante ou disjuntiva e um sintagma verbal.

Significado: um paciente expresso e não pressuposto sofre uma mudança de estado ou de condição causada por um agente.

Casos encontrados: 5 de 150. Exemplo: 
(7) Un locutor mendocino, preso por el homicidio de sus suegros

Construção 8. Estativa [SUJ ${ }_{-\mathrm{AG}} \mathrm{COP}$ ADJ (SP)].

Forma: SN seguido de uma cópula e um adjetivo predicativo seguido de um sintagma preposicional opcional.

Significado: um experienciador expresso e não pressuposto é associado a uma condição transitória sem causação identificada.

Casos encontrados: 4 de 150. Exemplo:

(8) Persecución fatal en San Miguel del Monte: los 13 acusados seguirán detenidos

A construção seguinte, como a primeira, guarda relação com a construção básica sujeito-verbo.

Construção 9. Inacusativa de mudança de estado de sujeito preverbal [SUJ ${ }_{-\mathrm{AG}}$ $\mathrm{V}(\mathrm{SP})]$.

Forma: SN seguido de verbo seguido de um sintagma preposicional opcional.

Significado: um paciente expresso não pressuposto e relevante experimenta uma mudança de estado náo provocada.

Casos encontrados: 1 de 150. Exemplo: 
O QUE DiZ UMA MANCHETE? UMA LEITURA CONSTRUCIONAL DE MANCHETES ARGENTINAS E BRASILEIRAS

(9) Mendoza. Dos hermanitos murieron en un incendio y sus padres están graves

As três seguintes são derivadas da construção básica verbo-sujeito. São elas a inacusativa de mudança de estado, a inacusativa de existência e aparição e a construção transitiva de sujeito posposto.

Construção 10. Inacusativa de mudança de estado [V SUJ $\left.{ }_{-\mathrm{AG}}\right]$.

Forma: Verbo seguido de SN.

Significado: um paciente expresso não pressuposto experimenta uma mudança de estado de causação interna.

Casos encontrados: 7 de 150. Exemplo:

(10) Persecución fatal en San Miguel: mejora Rocío y evalúan operarla

Construção 11. Inacusativa de existência e aparição [V (SP) SUJ ${ }_{-\mathrm{AG}}$ ]. Forma: Verbo seguido de SN.

Significado: um paciente expresso não pressuposto ganha existência ou torna a aparecer.

Casos encontrados: 4 de 150. Exemplo:

(11) San Miguel del Monte: hubo otro choque con dos muertos y un herido

Construção 12. Transitiva de sujeito posposto [V SUJ $\left.{ }_{\mathrm{AG}} \mathrm{OD}(\mathrm{SP})\right]$.

Forma: Verbo seguido de SN seguido de objeto direto seguido de um sintagma preposicional opcional. 
Significado: um paciente expresso não pressuposto ganha existência ou torna a aparecer.

Casos encontrados: 1 de 150. Exemplo:

(12) Cuestiona un empresario su imputación por lavado de dinero narco

O gráfico abaixo mostra as frequências token comparadas de cada construção no universo dos dados do espanhol:

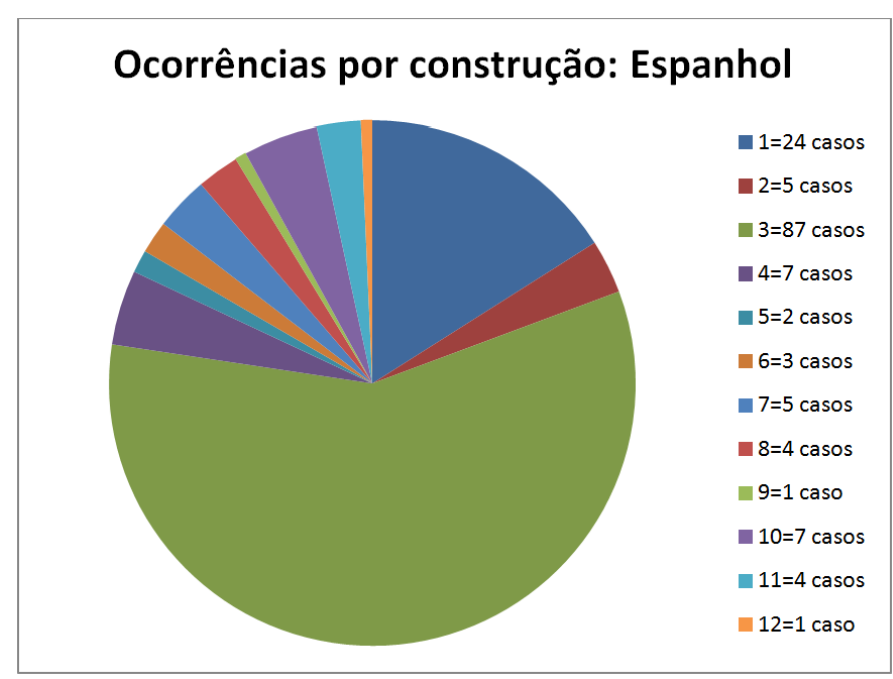

Figura 1: frequências token de cada um dos 12 types construcionais instanciados no espanhol.

As construçóes que foram instanciadas de maneira mais recorrente foram a 3, impessoal com verbo na $3^{a}$ pessoa do plural (58\%) e a transitiva (16\%). 
O QUE DiZ UMA MANCHETE? UMA LEITURA CONSTRUCIONAL DE MANCHETES ARGENTINAS E BRASILEIRAS

\subsection{Dados do PB.}

Identificamos cinco construções empregadas na veiculação das manchetes brasileiras, duas relacionadas à construção sujeito-verbo, a transitiva (que também herda propriedades da núcleo-complemento) e a inacusativa de mudança de estado e três, relacionadas à copulativa, a passiva, a passiva resultativa e a estativa. As contrapartes de quatro destas foram instanciadas nas manchetes argentinas, à exceção da passiva resultativa. Os dados brasileiros revelam uma dinâmica diferente, no que diz respeito à distribuição das construçóes, como será mostrado.

Construção 1 do PB. Transitiva $\left[\mathrm{SUJ}_{\mathrm{AG}} \mathrm{V}\right.$ OD (SP)].

Forma: dois argumentos em torno de um verbo, correspondendo ao sujeito e ao objeto, seguido de SPs opcionais.

Significado: um agente expresso, pressuposto ou não, relevante ou não age para

causar uma mudança de estado ou de condição numa entidade paciente. Casos encontrados: 81 do total de 150. Exemplo retirado do corpus:

(13) Polícia prende suspeito de agredir ex-mulher em Jacarepaguá

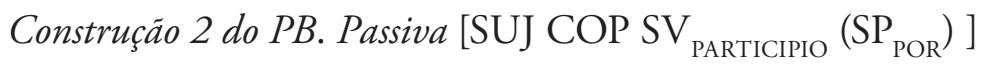

Forma: SN seguido de uma cópula e um particípio seguido de um sintagma preposicional opcional.

Significado: um paciente expresso, pressuposto ou não, relevante ou náo sofre uma mudança de estado ou de condição causada por um agente. 
Casos encontrados: 64 do total de 150. Exemplo:

(14) Homem é preso em flagrante após invadir prédio em Copacabana

Construção 3 do PB. Passiva resultativa [ $\mathrm{SUJ}_{-\mathrm{AG}} \mathrm{V}$ ADJ (SP) ].

Forma: $\mathrm{SN}$ seguido de uma cópula e um particípio seguido de um sintagma preposicional opcional.

Significado: um paciente expresso, pressuposto ou não, relevante ou não é apresentado no estado resultante após sofrer uma mudança de estado ou de condição de causa interna ou externa.

Casos encontrados: 1 do total de 150. Exemplo:

(15) Suspeito fica ferido em confronto na Zona Norte

Construção 4 do PB. Inacusativa de mudança de estado de sujeito preverbal [ $\left.\mathrm{SUJ}_{-\mathrm{AG}} \mathrm{V}(\mathrm{SP})\right]$.

Forma: SN seguido de verbo seguido de um sintagma preposicional opcional.

Significado: um paciente expresso não pressuposto e relevante experimenta uma mudança de estado náo provocada.

Casos encontrados: 3 do total de 150. Exemplo:

(16) Idosa morre após ser atropelada por ambulância em Madureira

Construção 5 do PB. Estativa [SUJ $\left.{ }_{-\mathrm{AG}} \mathrm{COP} \mathrm{ADJ}(\mathrm{SP})\right]$. 
O QUE DiZ UMA MANCHETE? UMA LEITURA CONSTRUCIONAL DE MANCHETES ARGENTINAS E BRASILEIRAS

Forma: SN seguido de uma cópula e um adjetivo predicativo seguido de um sintagma preposicional opcional.

Significado: um experienciador expresso, pressuposto ou não é associado a uma condição transitória.

Casos encontrados: 1 do total de 150. Exemplo:

(17) Designer baleado no rosto na BR-101 está fora de perigo; números apontam violência na via

O gráfico abaixo mostra as frequências token comparadas de cada construção no universo dos dados do PB:

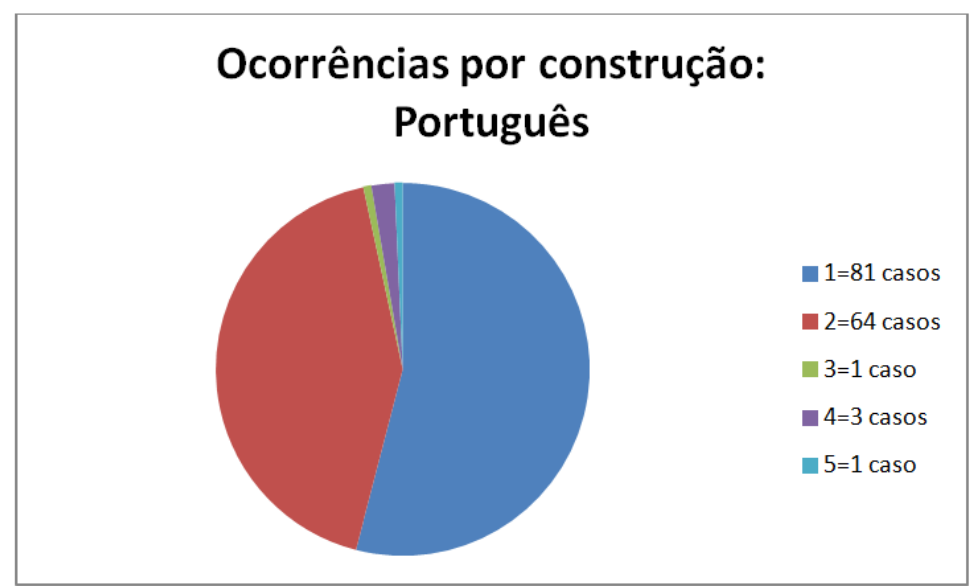

Figura 2: frequências token de cada um dos 12 types construcionais instanciados no PB. 
As construções que foram instanciadas no $\mathrm{PB}$ com mais recorrência foram a 1 , transitiva ( $54 \%$ dos dados) e a 2, passiva (43\% dos dados).

\section{DISCUSSÃO.}

Nesta seção, discutiremos características de funcionamento e propriedades das duas construçôes instanciadas mais frequentemente nas manchetes nos conjuntos de dados argentino e brasileiro, considerando tais construçóes como representativas das construçóes tipicamente encontradas no gênero manchete.

As construçôes instanciadas mais frequentemente nas manchetes do espanhol, de Buenos Aires, foram a impessoal com terceira pessoa do plural, que apareceu em $58 \%$ dos dados ( $\mathrm{n}=87$ ) e a transitiva, que apareceu em 16\% dos dados ( $\mathrm{n}=24)$. Nas do PB, do Rio de Janeiro, foram a transitiva, que apareceu em 54\% dos dados $(n=81)$ e a passiva, que apareceu em $43 \%$ dos dados ( $n=64)$. Nos dados do $\mathrm{PB}$ não houve casos de instanciação da impessoal com terceira pessoa do plural, preponderante no espanhol e quatro das construçóes instanciadas nas manchetes brasileiras também apareceram nos dados do espanhol, com exceção da passiva resultativa, que foi instanciada apenas nos dados do $\mathrm{PB}$, em 1 caso.

A construção impessoal com terceira pessoa do plural [V (SP) OBJ (SP)], instanciada na grande maioria das manchetes do espanhol compartilha com a passiva a característica semântica de impessoalidade, dentre aquelas elencadas por Givón (1994) para as passivas, pois nesta construção impessoal a identidade do agente é suprimida, bem como a sua expressão. 
O QUE DIZ UMA MANCHETE? UMA LEITURA CONSTRUCIONAL DE MANCHETES ARGENTINAS E BRASILEIRAS

Paulo Pinheiro Correa

Outra noção importante aqui é a de frame semântico (Fillmore, 1977, 1982; Fillmore; Baker, 2010). Um dos precursores da proposta da Semântica de Frames, Charles Fillmore, caracteriza um frame da seguinte maneira: “(...) qualquer sistema de conceitos relacionados de tal maneira que para entender qualquer deles é necessário compreender a estrutura inteira da qual ele faz parte" $^{3}$ (Fillmore, 1982, 111). De acordo com a Semântica de Frames, os itens que aparecem em determinada construção evocam as estruturas semânticas que possibilitam o seu entendimento. Estas emergem da experiência do dia a dia e são essenciais para compreender sentidos em contextualização adequada. Assim, os verbos e outros itens que instanciam as construçóes acionam os frames correspondentes para a interpretação de seu significado: verbos transitivos, por exemplo, acionam a existência de um agente e um paciente na cognição do interlocutor. Independentemente de estes participantes serem expressos ou não, eles são categorias com as quais o interlocutor tem que lidar e que são indispensáveis para o entendimento do enunciado.

Goldberg (1995, 56-58), trata das propriedades das construções de estrutura argumental, no que diz respeito à expressão ou não dos participantes acionados em um frame em determinada construção. De acordo com a autora, algumas construçóes têm a propriedade de colocar um participante à sombra, fora de evidência, enquanto outras podem cortar ou eliminar a expressão do participante. No caso da impessoal com terceira pessoa do plural,

3 Traduzido por nós do original em inglês: (...) any system of concepts related in such a way that to understand any one of them you have to understand the whole structure in which it fits (...) 
esta tem o poder de cortar o agente acionado no frame. Já a passiva tem o poder de sombrear este participante.

A impessoal com terceira pessoa do plural foi objeto de estudo de Fernández Soriano (1999, 1738), que assinala que esta tem referência não genérica e não universal, isto é, se aplica a participantes reais, ainda que estes sejam gramaticalmente indefinidos ou indeterminados.

Aqui entra em jogo a função ou o significado da construção escolhida para veicular o fato anunciado. E está relacionada à escolha daquilo que vem a ser considerado relevante a ponto de ser noticiado na manchete. Esta questão é captada por Fernández Soriano (1999), ao discutir sobre a possibilidade de os agentes das impessoais serem semanticamente definidos e determinados:

(...) otra característica de las oraciones impersonales con tercera persona del plural es que en ellas ni el emisor ni el receptor participan en la identificación de la citada referencia personal. El uso de la tercera persona del plural (sin soporte pronominal) se produce bien porque el hablante desconoce totalmente el referente de dicha persona, bien porque no tiene ningún interés en especificarlo, aunque lo conozca. A veces, el hecho de que el hablante no desee explicitar la referencia al sujeto no se debe tanto a su desinterés como a la influencia de factores pragmáticos. (Fernández Soriano, 1999, 1739)

Assim, os participantes presentes no frame acionado pelo verbo que instancia a construção podem deixar de ser expressos: (i) por questóes semânticas (quando são previstos no frame instaurado pelo verbo, por conhecimento de mundo) ou (ii) por questôes de relevância pragmática, quando não acrescentam informação relevante que contribua na interpretação do conteúdo. 
O QUE DIZ UMA MANCHETE? UMA LEITURA CONSTRUCIONAL DE MANCHETES ARGENTINAS E BRASILEIRAS

No caso desta construçáo, ela contribui na interpretaçáo do fato que é expresso por seu intermédio, com a informação pragmática de que o sujeito é irrelevante para a compreensão da notícia. No que se refere à estrutura informativa, o verbo em primeira posição atribui à construçáo a leitura de notícia inédita, na qual nenhum dos componentes é previsto naquele noticiário. Isto pode ser observado no exemplo (3), repetido aqui como (18):

(18) Mataron en Moreno a un comisario de San Isidro para robarle el auto

No exemplo, o agente previsto no frame ativado por 'matar' é lido como desconhecido e, principalmente, irrelevante para a apreensão do fato, que é o assassinato de um delegado.

Já a construção transitiva $\left[\mathrm{SUJ}_{\mathrm{AG}} \mathrm{V} \mathrm{OD}(\mathrm{SP})\right]$ se diferencia radicalmente da impessoal por prever a expressáo de um sujeito agente e a escolha de uma construção que expressa o sujeito conduz à leitura de que esse agente é semanticamente não predizível pelo frame e que sua identificação é pragmaticamente relevante para a apreensão do conteúdo veiculado. No exemplo (1), repetido aqui como (19),

(19) Un policia golpeó y amenazó de muerte a un chico de 17 años frente a una escuela 
o agente não é previsto no frame porque contraria a expectativa social que se tem do comportamento de um policial, associado ao frame SEGURANÇA e a sua expressão passa a ser indispensável para a compreensão de por que o fato é notícia.

O contraste entre estas escolhas construcionais (com identificação plena de agente e paciente; com omissão de agente e identificação de paciente) descortina uma motivação estruturada para a expressão/não expressão dos participantes na manchete argentina, ligada à previsibilidade semântica e à relevância pragmática dos participantes acionados nos frames particulares.

Nas construçôes instanciadas nos dados brasileiros, as restrições de relevância de base griceana aparentemente operantes nas manchetes argentinas não parecem operar na construção transitiva e são atendidas de maneira apenas parcial na construção passiva. $\mathrm{Na}$ construção transitiva $\left[\mathrm{SUJ}_{\mathrm{AG}} \mathrm{V}\right.$ $\mathrm{OD}(\mathrm{SP})]$ brasileira foram veiculados agentes semanticamente previsíveis e pragmaticamente irrelevantes, o que será ilustrado aqui pelo exemplo (13), repetido aqui como (20):

(20) Polícia prende suspeito de agredir ex-mulher em Jacarepaguá

No caso de atendimento radical à máxima de relevância griceana, como nas manchetes argentinas, o sujeito aqui só seria expresso se quem efetuou o ato de prender fosse um civil, por exemplo, porque o agente 'polícia' é o candidato mais previsível a agente no frame acionado pelo verbo 'prender", de maneira que este é irrelevante para o entendimento do fato noticiado. 
O QUe diZ UMa MANCHETE? UMA LEITURA CONSTRUCIONAL DE MANCHETES ARgENTINAS E BRASILEIRAS

Paulo Pinheiro Correa

Houve casos de sujeitos imprevisíveis e relevantes, mas a grande maioria dos dados expressava o sujeito 'polícia' para verbos do tipo 'prender/apreender/ recuperar/investigar' e 'criminosos' e 'bandidos' para verbos do tipo 'roubar', que não atendem a estes requisitos.

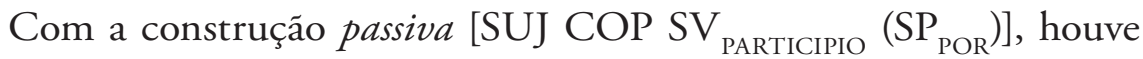
atendimento parcial da máxima de relevância. O exemplo (14), repetido aqui como (21) ilustra a questão:

(21) Homem é preso em flagrante após invadir prédio em Copacabana

Neste caso, o agente, previsto no frame ativado por 'prender' foi omitido através da escolha da construçáo, mas o sujeito experienciador/paciente, indeterminado e irrelevante foi expresso. Houve diversos casos de sujeitos imprevisíveis no frame ativado pelo verbo e, portanto, relevantes, mas os sujeitos indeterminados e irrelevantes caracterizaram os casos que instanciaram a construção passiva no corpus, de maneira que a grande maioria dos sujeitos foram os SNs 'homem' e 'mulher', irrelevantes e indeterminados, havendo mais de um caso também de 'suspeito' e de 'bandidos', participantes previsíveis no frame instaurado pelo verbo e indeterminados.

A descrição, na seção anterior, e a comparação entre as construçôes mais representativas dos dados do corpus mostram que as construções do espanhol são especializadas na veiculação de significados que se combinam com os significados dos verbos que as instanciam, o que ajuda a precisar sentidos e impede leituras inadequadas. Por outro lado, a comparação com os dados brasileiros mostra 
que a construção transitiva, instanciada na maioria das manchetes não impede leituras inadequadas nem conduz a leituras precisas quanto à previsibilidade è̀ relevância de seus sujeitos. A construção passiva, quase tão usada quanto a anterior tampouco conduz a leituras precisas quanto à previsibilidade e à relevância dos seus sujeitos, permitindo, porém, que seja inferida a relevância/irrelevância de seus agentes.

As construções argentinas instanciadas no corpus se dividiram entre construçóes encabeçadas pelo verbo e encabeçadas pelo sujeito (113 tokens do primeiro grupo e 37 tokens do segundo grupo), enquanto os dados brasileiros foram todos de construçóes encabeçadas pelo sujeito. Esta ausência de diferença também tem implicaçóes de estrutura informativa, pois a ausência de agente ou sua localização em posição pós-verbal auxilia a identificação dos conteúdos como manchetes novas ou manchetes de atualização de noticiário (tópico-comentário) nos dados do espanhol, o que fica opaco nos dados do português, que apresentam sujeitos tanto relevantes quanto irrelevantes e tanto novos quanto dados todos da mesma forma, sem pistas construcionais para o leitor.

\section{CONCLUSÃO}

A análise das construções instanciadas nas manchetes em espanhol argentino revelou uma gama de 12 tipos construcionais e a das construçóes instanciadas em PB revelou 5 tipos. Das manchetes argentinas as duas construçôes mais recorrentes, a impessoal com sujeito na terceira pessoal do 
O QUe diZ UMA MANCHETE? UMA LEITURA CONSTRUCIONAL DE MANCHETES ARgENTINAS E BRASILEIRAS

plural e a transitiva diferiram tipologicamente em que a primeira, encabeçada por um verbo, tem a função, entre outras, de impedir a expressão de agentes irrelevantes para a compreensão do conteúdo, enquanto que a segunda mais frequente, a transitiva, é escolhida para expressar agentes não previstos no frame semântico e que são relevantes para a compreensão do fato veiculado.

A grande maioria das manchetes do $\mathrm{PB}$, por outro lado, instanciou a construção transitiva e a passiva. Ambas se caracterizam por apresentarem um sujeito expresso e em posição preverbal. A obediência à máxima de relevância griceana que caracterizou as construçóes dos dados argentinos não foi observada nos dados brasileiros da mesma forma: nas construçôes transitivas foram veiculados agentes indeterminados, semanticamente previsíveis e pragmaticamente irrelevantes. Nas construçóes passivas, agentes previsíveis deixaram de ser expressos, mas a maioria dos dados apresentou a expressão de sujeitos pacientes irrelevantes para a compreensão dos conteúdos.

Tal comparação mostrou uma especialização nos significados das diferentes construçôes nos dados argentinos, cujo significado complementa o sentido do conteúdo veiculado, conduzindo a uma leitura adequada e impedindo leituras equivocadas. Com os dados do PB não se pôde observar o mesmo, já que as construçôes ao veicularem tanto sujeitos semanticamente previsíveis quanto imprevisíveis e tanto pragmaticamente relevantes quanto irrelevantes não balizam a leitura e não impedem leituras equivocadas, deixando para o leitor maior trabalho interpretativo.

No que se refere à estrutura informativa, a variedade de construçóes observada nos dados de espanhol permite auxiliar na diferenciação entre manchetes de 
conteúdo inteiramente novo daquelas de atualização do noticiário, por meio da expressão, ocultamento e sombreamento de agentes. Nos dados do PB, todos os dados eram de sujeito expresso e anteposto, o que indiferencia estruturalmente sujeitos novos de dados, e, por conseguinte, manchetes de conteúdo novo, por um lado e de tópico-comentário, de atualização do noticiário, por outro, exigindo decisão unicamente do leitor, também neste quesito.

\section{REFERÊNCIAS BIBLIOGRÁFICAS.}

Abraçado, Jussara; Silva, Caroline S. "Manchetes de jornais online: graus de transitividade e emprego do presente do indicativo em referência ao passado recente”. In: Confluência, Rio de Janeiro, no. 46, 2014. 221-50.

Alarcos Llorach, Emilio. “Lenguaje de los titulares”. In: Lázaro Carreter, Fernando (org.). Lenguaje en periodismo escrito. Madrid: Fundación Juan March, 1977, 125-148.

Bybee, Joan. Language, usage and cognition. Cambridge: Cambridge University Press, 2010.

Barros Filho, Clóvis. Ética na Comunicação - Revista e Atualizada. 6. ed. São Paulo: Summus, 2008.

Fernández Soriano, Olga. "El pronombre personal. Formas y distribuciones. Pronombres átonos y tónicos”. In: Bosque, Ignacio; Demonte, Violeta. (orgs.). Gramática Descriptiva de la Lengua Española. Madrid: Espasa, 1999, 1209-1273.

Fillmore, Charles. J. "Scenes-and-frames semantics”. In: Zampolli, Antonio. (ed.): Linguistic Structures Processing: Fundamental Studies in Computer Science, No. 59, North Holland Publishing, 1977, 55-88.

Fillmore, Charles. "Frame semantics". In: The Linguistic Society of Korea (Ed.). Linguistics in the Morning Calm. Seoul: Hanshin Publishing Co., 1982, 111-137. 
O QUE DIZ UMA MANCHETE? UMA LEITURA CONSTRUCIONAL DE MANCHETES ARGENTINAS E BRASILEIRAS

Fillmore, Charles. J.; Baker, Collin. "A Frames Approach to Semantic Analysis". In: Heine, Bernd; Narrog, Heiko (Eds.). The Oxford Handbook of Linguistic Analysis. New York: Oxford University Press, 2010, 313-340.

Givón, Talmy. "The pragmatics of de-transitive voice: functional and typological aspects of inversion”. (Introduction). In: Givón, Talmy (ed.). Voice and Inversion. Amsterdam: John Benjamins Publishing, 1994, 3-46.

Goldberg, Adele E. Constructions: A Construction Grammar Approach to Argument Structure. Chicago: University of Chicago Press, 1995.

Goldberg, Adele E. Constructions at work. The nature of generalization in language. New York: Oxford University Press, 2006.

Lambrecht, Knud. Information structure and sentence form. Topic, focus, and the mental representations of discourse referents. Cambridge: Cambridge University Press, 1994.

Lambrecht, Knud. "When subjects behave like objects: An analysis of the merging of $S$ and $O$ in sentence-focus constructions". Studies in Language, v. 24., n. 3, 2000.

Langacker, Ronald W. Foundations of Cognitive Grammar (Vol. 1). Theoretical Prerequisites. Stanford: Stanford University Press, 1987.

Nadal Palazón, Juan. "Rasgos formales de los titulares periodísticos: notas sobre diez diarios del ámbito hispánico”. In: Acta Poética, v.33, n.1, 2012, 173-95.

Sasse, Hans-Jürgen. Theticity. In: Bernini, Giuliano; Scwharz, Marcia L. (eds.). Pragmatic organization of discourse in the languages of Europe. Berlin: Mouton de Gruyter, 2006, 257-308. 